\title{
Assessment of Self-Medication of Antibiotics in a Jordanian Population
}

\author{
Faleh A. Sawair Zaid H. Baqain Ashraf Abu Karaky Rasha Abu Eid \\ Department of Oral and Maxillofacial Surgery, Oral Medicine, Oral Pathology and Periodontology, \\ Faculty of Dentistry, The University of Jordan, Amman, Jordan
}

\section{Key Words}

Antibiotics $\cdot$ Self-medication $\cdot$ Jordan

\begin{abstract}
Objective: To assess the extent of self-medication with antibiotics (SMA) in a Jordanian population, and to evaluate the sociodemographic factors affecting this behaviour. Subjects and Methods: Face-to-face interviews were conducted with 477 patients aged 16-65 years attending the Department of Dentistry, University of Jordan Hospital. Socio-demographic data were collected and interviewees were asked about their SMA behaviour during the last 6 months, the reasons and motives for this behaviour, and the source and dose of the antibiotics were noted. Results: The prevalence rate of SMA in the sample during the 6 months preceding the interview was $40.7 \%$ (194/477). Patients aged 36-55 years and those in the middle-class income group were most likely to perform SMA. SMA was mainly for sore throats, common colds and dental infections, and community pharmacies were the major source (104, 53.6\% cases). Amoxicillin was the most commonly used antibiotic, and only 73 (37.6\%) patients followed the correct dosage guidelines. Previous experience with similar illness and saving time were the most common reasons for SMA. Ninety-four (19.7\%) patients admitted that they consulted another physician to obtain antibiotics when
\end{abstract}

their first physician did not prescribe any. Conclusion: The findings showed that SMA was a frequent practice among Jordanians, signifying the need for an educational campaign on the proper use of antibiotics in this population.

Copyright $\odot 2008$ S. Karger AG, Basel

\section{Introduction}

The irrational use and overuse of antibiotics continue to be a global problem, despite the increased risks of adverse effects and drug resistance [1]. Effective intervention, by studying the factors leading to this phenomenon, is therefore of particular importance, principally in developing countries that are home to the majority of the world's population. We have previously reported, the lack of consistency in the rational use of antibiotics by Jordanian practitioners, with considerable variations from the recommended guidelines [2]. It is to be expected that such prescribing habits can enhance patient belief that antibiotics can fight any disease without specific guidelines for their use, and subsequently increase the pressure on practitioners for clinically unnecessary prescriptions, and reinforce the behaviour of self-medication with antibiotics (SMA) [3]. Despite the increasing recognition that SMA is widespread in developing countries, there are few

\section{KARGER}

Fax +41613061234

E-Mail karger@karger.ch

www.karger.com
(C) 2008 S. Karger AG, Basel

1011-7571/09/0181-0021\$26.00/0

Accessible online at:

www.karger.com/mpp
Faleh Sawair, BDS, FDSRCS (Eng.), PhD

Faculty of Dentistry

The University of Jordan

Amman 11942 (Jordan)

Tel. +962 65355000 ext. 23595, E-Mail sawair@ju.edu.jo 
Table 1. Examples of similar studies showing the widespread problem of SMA

\begin{tabular}{llll}
\hline Study & Country & Time period & $\begin{array}{l}\text { SMA }^{2} \\
\%\end{array}$ \\
\hline & & & \\
\hline Calva and Bojalil [6] & Mexico & previous 2 weeks & 5 \\
Svensson et al. [7] & Sweden & previous 12 months & 17 \\
Borg and Scicluna [8] & Malta & unspecified & 19.2 \\
Saradamma et al. [9] & India & previous 2 weeks & 21.2 \\
Vaananen et al. [10] & Finland & previous 6 months & 28 \\
Berzanskyte et al. [11] & Lithuania & previous 12 months & 39.9 \\
Current study & Jordan & previous 6 months & 40.7 \\
Richman et al. [12] & USA & previous 12 months & 43 \\
Cagri Buke et al. [13] & Turkey & unspecified & 45.8 \\
Awad et al. [4] & Sudan & previous 1 month & 48.1 \\
Bi et al. [14] & China & previous 12 months & 59.4 \\
Mitsi et al. [3] & Greece & unspecified & 74.6 \\
\hline
\end{tabular}

${ }^{1}$ The time frame specified in the survey during which the patients took the antibiotics without prescription.

${ }^{2}$ Percentage of study population who took antibiotics without prescription.

studies that shed light on the subject $[4,5]$. This study was conducted to assess the extent of SMA among Jordanians, and to identify sociodemographic factors related to this behaviour.

\section{Subjects and Methods}

A survey was conducted of patients attending dental clinics at the Department of Dentistry at the University of Jordan Hospital. In this teaching hospital, both speciality and student clinics offer dental treatment for patients living in the capital city of Amman and its nearby villages and refugee camps. The clinics have an annual attendance in excess of 200,000 patients. The study sample was randomly selected from patients attending these clinics from November 2005 to March 2006. Trained teaching and research assistants carried out face-to-face interviews in Arabic with 477 patients aged 16-65 years. A structured questionnaire was pretested on a small pilot population (20 patients) to address any ambiguity in the questions, and to determine whether or not the data obtained provided reliable information. The data collected were made anonymous. Verbal consent was obtained before all interviews. The demographic data included age, gender, marital and employment status, household monthly income, level of education, type of insurance, smoking habits, self-reported health status and chronic morbidity. Interviewees were then asked if they had taken antibiotics in the last 6 months without consulting a physician. If participants answered yes, they were then asked about the symptom (disease) for which they took the antibiotics. The source, name, dosage, duration and frequency of the intake were noted. Interviewees were also asked for the reasons for the
SMA behaviour, and whether or not they had ever asked another physician to give them antibiotics prescription when the first one had refused to do so.

Statistical analysis was performed using SPSS for Windows version 14.0 (SPSS, Chicago, Ill., USA) and $\chi^{2}$ tests were used to determine the associations between sociodemographic factors and SMA and other outcome measures. Stepwise multivariate logistic regression was then used to control for potential confounding variables and to calculate the odds ratios for potential independent variables for SMA. Statistical significance was set at $\mathrm{p}<$ 0.05 .

\section{Results}

Of the 477 patients interviewed, 194 (40.7\%) took antibiotics without a prescription. Comparative SMA rates from other countries are shown in table 1. The demographic characteristics of the patients are given in table 2 . Age and household monthly income significantly affected SMA ( $p=0.03$ and 0.04 , respectively), and medical insurance was very close to statistical significance $(\mathrm{p}=$ 0.06 ). The multivariate regression analysis maintained the importance of age and income as independent risk indicators of SMA (table 3).

The sources of the non-prescribed antibiotics were as follows: pharmacy, 104 (53.6\%); a previous treatment, 70 (36.1\%); relatives and friends, 20 (10.3\%). The pharmacy was the most common source for men, while unused antibiotics from a previous treatment was the most common source for women $(\mathrm{p}<0.01)$. SMA was mainly for symptoms of a sore throat $(65 ; 33.5 \%)$, common cold (51; $26.3 \%$ ) and dental infections (31; 16.0\%) (fig. 1). Amoxicillin was the most commonly self-prescribed antibiotic (142; 78.9\%), followed by metronidazole (10; 5.6\%) and cephalosporins $(7 ; 3.9 \%)$. Of the 194 that used non-prescription antibiotics, only 73 (37.6\%) followed the correct dosage guidelines. Level of education $(p<0.01)$ and medical insurance $(p=0.001)$ seemed to affect the dosage, i.e. as the level of education and insurance increased, the patients tended to adhere better to dosage guidelines. Reasons for use of non-prescription antibiotics are shown in figure 2. In total, 103 (53.1\%) patients reported that previous experience with similar illness and knowledge of the drugs that were prescribed by their doctors were the reasons for their SMA. An additional 57 (29.4\%) said that SMA was easier and less time-consuming. Of the 477, 94 (19.7\%) admitted that they consulted a second physician to obtain antibiotics when their first physician did not prescribe any. This behaviour occurred more often in patients who were illiterate or had only primary or secondary school education $(\mathrm{p}<0.01)$. 
Table 2. Sociodemographic characteristics of the patients

\begin{tabular}{|c|c|c|c|}
\hline Variable & $\begin{array}{l}\text { Subjects } \\
\text { studied } \\
(\mathrm{n}=477)\end{array}$ & $\begin{array}{l}\text { Self- } \\
\text { medication } \\
(\mathrm{n}=194)\end{array}$ & $\mathrm{p}$ value \\
\hline Gender & & & 0.92 \\
\hline Male & $220(46.1)$ & $90(46.4)$ & \\
\hline Female & $257(53.9)$ & $104(53.6)$ & \\
\hline Age (years) & & & 0.03 \\
\hline $16-25$ & $201(42.1)$ & $80(41.2)$ & \\
\hline $26-35$ & $67(14.0)$ & $25(12.9)$ & \\
\hline $36-45$ & $85(17.8)$ & $41(21.1)$ & \\
\hline $46-55$ & $57(11.9)$ & $29(15.0)$ & \\
\hline $56-65$ & $42(8.8)$ & $15(7.7)$ & \\
\hline$>65$ & $25(5.2)$ & $4(2.1)$ & \\
\hline Marital status & & & 0.29 \\
\hline Single & $223(46.8)$ & $85(43.8)$ & \\
\hline Married & $254(53.2)$ & $109(56.2)$ & \\
\hline Education & & & 0.90 \\
\hline Illiterate & $14(2.9)$ & $7(3.6)$ & \\
\hline Primary school & $37(7.8)$ & $15(7.7)$ & \\
\hline Secondary school & $90(18.9)$ & $35(18.0)$ & \\
\hline High school & $113(23.7)$ & $42(21.7)$ & \\
\hline University degree & $198(41.5)$ & $85(43.8)$ & \\
\hline Postgraduate & $25(5.2)$ & $10(5.2)$ & \\
\hline Occupation & & & 0.51 \\
\hline Working & $160(33.5)$ & $72(37.1)$ & \\
\hline Retired & $41(8.6)$ & $14(7.2)$ & \\
\hline Unemployed & $52(10.9)$ & $19(9.8)$ & \\
\hline Housewife & $107(22.4)$ & $46(23.7)$ & \\
\hline Student & $117(24.5)$ & $43(22.2)$ & \\
\hline Monthly income (JOD) & & & 0.04 \\
\hline$<200$ & $140(29.4)$ & $46(23.7)$ & \\
\hline $200-400$ & $133(27.9)$ & $63(32.5)$ & \\
\hline$>400$ & $204(42.8)$ & $85(43.8)$ & \\
\hline Self-reported health & & & 0.60 \\
\hline Good & $355(74.4)$ & $149(76.8)$ & \\
\hline Intermediate & $99(20.8)$ & $36(18.6)$ & \\
\hline Poor & $23(4.8)$ & $9(4.6)$ & \\
\hline Chronic morbidity & & & 0.17 \\
\hline No & $353(74.0)$ & $150(77.3)$ & \\
\hline Yes & $124(26.0)$ & $44(22.7)$ & \\
\hline Smoking & & & 0.17 \\
\hline No & $336(70.4)$ & $130(67.0)$ & \\
\hline Yes & $141(29.6)$ & $64(33.0)$ & \\
\hline Insurance & & & 0.06 \\
\hline Uninsured & $129(27.0)$ & $55(28.4)$ & \\
\hline Partial insurance ${ }^{1}$ & $90(18.9)$ & $45(23.2)$ & \\
\hline Full insurance & $258(54.1)$ & $94(48.5)$ & \\
\hline
\end{tabular}

Figures in parentheses are percentages. Statistical analyses were performed with $\chi^{2}$ tests. JOD $=$ Jordanian dinar $($ JOD $1=\mathrm{ca}$. KWD 0.38/USD 1.4).

${ }^{1}$ Covering $70-80 \%$ of treatment cost.
Table 3. Stepwise logistic regression modelling for SMA

\begin{tabular}{|c|c|c|c|c|}
\hline Variable & $\begin{array}{l}\text { Regression } \\
\text { coefficient }\end{array}$ & $\mathrm{p}$ value & $\begin{array}{l}\text { Odds } \\
\text { ratio }\end{array}$ & $\begin{array}{l}\text { Confidence } \\
\text { limits for } \\
\text { odds ratio }\end{array}$ \\
\hline \multicolumn{2}{|c|}{ Monthly income (JOD) } & 0.033 & & \\
\hline$<200$ & \multicolumn{2}{|c|}{ reference category } & 1.00 & \\
\hline $200-400$ & 0.664 & 0.009 & 1.94 & $1.18-3.21$ \\
\hline$>400$ & 0.300 & 0.203 & 1.35 & $0.85-2.14$ \\
\hline Age (years) & & 0.044 & & \\
\hline $16-25$ & 1.303 & 0.024 & 3.68 & $1.19-11.37$ \\
\hline $26-35$ & 1.171 & 0.054 & 3.22 & $0.98-10.58$ \\
\hline $36-45$ & 1.648 & 0.006 & 5.20 & $1.62-16.70$ \\
\hline $46-55$ & 1.790 & 0.004 & 5.99 & $1.78-20.12$ \\
\hline $56-65$ & 1.136 & 0.077 & 3.11 & $0.88-10.97$ \\
\hline$>65$ & \multicolumn{2}{|c|}{ reference category } & 1.00 & \\
\hline
\end{tabular}

\section{Discussion}

Studies on factors associated with antibiotic misuse are important to prevent the occurrence of antibiotic resistance. SMA is a well-known problem, as shown in table 1 . However, it is difficult to compare studies in different countries due to the absence of homogeneous samples and variable recall periods, which ranged from unspecified to 12 months. This survey revealed that SMA was common in Jordan, when compared with studies done in Europe with 6-month recall periods [10], and even 12month recall periods $[7,11]$.

With the exception of age and monthly income, the current study did not reveal any significant association between sociodemographic factors and SMA. It is unclear why patients with middle-level income self-medicate more frequently than others. It is possible that they could afford to buy antibiotics from pharmacies, but could not afford to visit physicians and buy the prescribed medications later. In contrast to another report [3], where SMA was more prevalent in elderly patients ( $>65$ years of age), our study showed the least intake of non-prescribed antibiotics among this age group, possibly due to the small number of patients studied.

Notwithstanding the many health risks of the inappropriate use of antibiotics [15], there was a great deal of unnecessary use of these drugs by the population investigated. The vast majority of subjects used antibiotics to relieve and cure predominantly viral upper respiratory tract infections and treat dental infections without visiting their dentists. Ignorance of the appropriate use of an- 
Fig. 1. Reported symptoms/diseases for SMA. Others $=$ Arthritis (2 cases), skin infections ( 2 cases), earache ( 2 cases) and 1 case took antibiotics for exams.
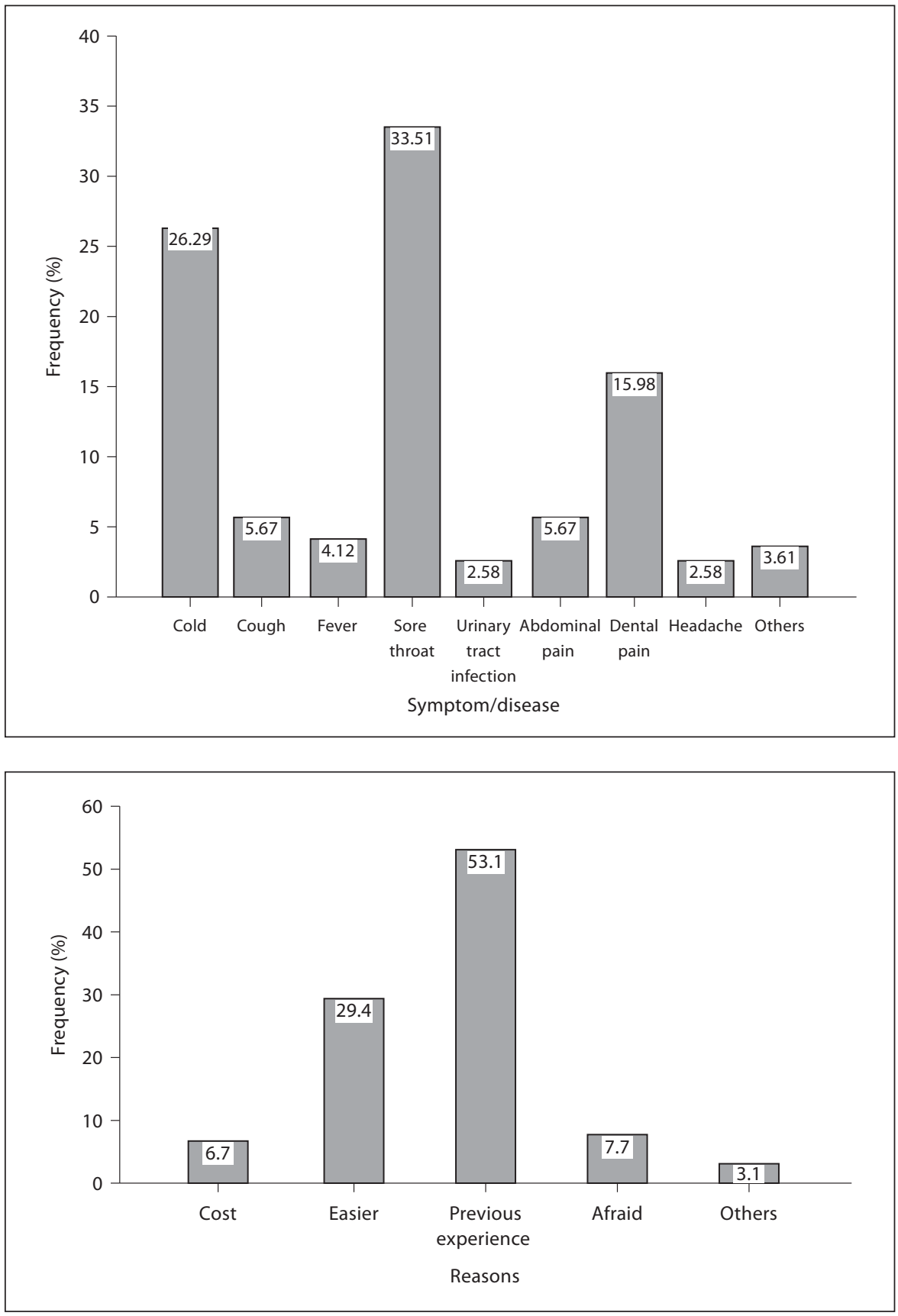

Fig. 2. Reasons for SMA.

resist colonization of harmful micro-organisms, thereby leading to super infections by multi-resistant bacteria and yeasts [16]. Based on our finding, inappropriate use of antibiotics was due to lack of patients' awareness and inappropriate prescriptions of antibiotics.

Previously, we had shown that the Jordanian general practitioners inappropriately prescribed antibiotics and poorly adhered to recommended guidelines for optimum 
dosage and course duration [2], as shown in other studies $[17,18]$. Thus, the inappropriate prescription of antibiotics encouraged patients' frequent use of them for the wrong diseases, and could lead to the belief that antibiotics should routinely be available at home. Hence, it was not surprising that nearly one fifth of the patients surveyed in this study had sought the prescription of antibiotics from a second doctor when the first refused to prescribe. The frequent prescription of antibiotics by physicians has led to an increasing number of patients strongly believing that they have experience of correctly using antibiotics, which is encouraging SMA.

Self-medication with antibiotics in Jordan may also be a consequence of poor control over community pharmacies, where buying non-prescription antibiotics is common, as revealed by the findings of this study. The storage of leftover antibiotics in the home constituted another important source of self-medication. The leftover antibiotics could be due to over-prescription or non-compliance by the patient. Therefore, it is important for physicians to appropriately prescribe the correct dosage, and to properly instruct patients to complete the antibiotic courses and discard any leftovers.

\section{Conclusion}

Inappropriate SMA appears to be common among Jordanians, signifying the need for carefully designed antibiotic educational campaigns to emphasize the uses and limitations of these medications, and to make the public aware of their negative effects, especially with respect to self-medication. This campaign should target the whole Jordanian community.

\section{References}

1 Martínez JL, Baquero F, Andersson DI: Predicting antibiotic resistance. Nat Rev Microbiol 2007;5:958-965.

2 Sawair FA: Antibiotic prescription by general dental practitioners in the management of acute dentoalveolar infections. Saudi Dent J 2006;18:112-117.

3 Mitsi G, Jelastopulu E, Basiaris H, Skoutelis A, Gogos C: Patterns of antibiotic use among adults and parents in the community: a questionnaire-based survey in a Greek urban population. Int J Antimicrob Agents 2005; 25:439-443.

4 Awad A, Eltayeb I, Matowe L, Thalib L: Selfmedication with antibiotics and antimalarials in the community of Khartoum State, Sudan. J Pharm Pharm Sci 2005;8:326-331.

$\checkmark 5$ Aboul Fotouh AM, el-Damaty SE, Abdel Megeid FY: Mother's knowledge about antibiotic and role of self prescription. J Egypt Public Health Assoc 1998;73:57-69.

6 Calva J, Bojalil R: Antibiotic use in a periurban community in Mexico: a household and drugstore survey. Soc Sci Med 1996;42:11211128 .
7 Svensson E, Haaijer-Ruskamp FM, Lundborg CS: Self-medication with antibiotics in a Swedish general population. Scand J Infect Dis 2004;36:450-452.

$>8$ Borg MA, Scicluna EA: Over-the-counter acquisition of antibiotics in the Maltese general population. Int J Antimicrob Agents 2002;20:253-257.

$\checkmark 9$ Saradamma RD, Higginbotham N, Nichter $\mathrm{M}$ : Social factors influencing the acquisition of antibiotics without prescription in Kerala State, south India. Soc Sci Med 2000;50:891903.

10 Vaananen MH, Pietila K, Airaksinen M: Self-medication with antibiotics - does it really happen in Europe? Health Policy 2006; 77:166-171

11 Berzanskyte A, Valinteliene R, Haaijer-Ruskamp FM, Gurevicius R, Grigoryan L: Selfmedication with antibiotics in Lithuania. Int J Occup Med Environ Health 2006;19:246253.

12 Richman PB, Garra G, Eskin B, Nashed AH, Cody R: Oral antibiotic use without consulting a physician: a survey of ED patients. Am J Emerg Med 2001;19:57-60.
13 Cagri Buke A, Ermertcan S, Hosgor-Limoncu M, Ciceklioglu M, Eren S: Rational antibiotic use and academic staff. Int J Antimicrob Agents 2003;21:63-66.

14 Bi P, Tong S, Parton KA: Family self-medication and antibiotics abuse for children and juveniles in a Chinese city. Soc Sci Med 2000; 50:1445-1450.

15 Byarugaba DK: A view on antimicrobial resistance in developing countries and responsible risk factors. Int J Antimicrob Agents 2004;24:105-110.

16 Longman LP, Martin MV: The use of antibiotics in the prevention of postoperative infection: a reappraisal. Br Dent J 1991;170: 257-262.

17 Gonzales R, Steiner JF, Sande MA: Antibiotic prescribing for adults with colds, upper respiratory tract infections, and bronchitis by ambulatory care physicians. JAMA 1997; 278:901-904.

18 Nyquist AC, Gonzales R, Steiner JF, Sande MA: Antibiotic prescribing for children with colds, upper respiratory tract infections, and bronchitis. JAMA 1998;279:875-877. 